Pacific Journal of Mathematics

NON-EXISTENCE OF ALMOST-COMPLEX STRUCTURES ON 


\title{
NON-EXISTENCE OF ALMOST-COMPLEX STRUCTURES ON QUATERNIONIC PROJECTIVE SPACES
}

\author{
W. S. MASSEY
}

1. Introduction. In [3] F. Hirzebruch proved that the $n$-dimensional quaternionic projective space (which we denote by $P_{n}(\boldsymbol{H})$ ) does not admit any almost structure in case $n \neq 2$ or 3 . According to Hirzebruch's lecture at the 1958 International Congress [5], Milnor has since proved that $P_{2}(\boldsymbol{H})$ and $P_{3}(\boldsymbol{H})$ do not admit almost complex structures. At the time of this writing, Milnor's proof has not yet been published.

It is the purpose of this note to give a short proof of this theorem of Milnor's making use of the theory of the ring $K(X)$ of complex vector bundles over a space $X$ due to Atiyah and Hirzebruch together with certain facts that are readily available in the literature. From the brief description given in Hirzebruch's lecture (loc. cit.) it seems that our method is quite different from Milnor's. Our method may be applicable in other cases to prove the existence or nonexistence of almost complex structures on a manifold.

2. Summary of some known facts. We will make use of the following results:

(a) The cohomology ring $H^{*}\left(P_{n}(\boldsymbol{H}), Z\right)$ is a truncated polynomial ring generated by a 4-dimensional cohomology class $u$ and subject to the single relation $u^{n+1}=0$.

(b) Let $\tau_{n}$ denote the tangent bundle to $P_{n}(\boldsymbol{H})$. The total Pontrjagin class of $\tau_{n}$ is given by the formula

$$
p\left(\tau_{n}\right)=(1+u)^{2 n+2}(1+4 u)^{-1}
$$

for appropriate choice of the generator $u$ (Borel and Hirzebruch [2], 15.5 or Hirzebruch [3]).

(c) We will use the following notation: If $\xi$ is a real $n$-plane bundle, then $\xi \otimes \boldsymbol{C}$ denotes its complexification, while if $\xi$ is a complex $n$-plane bundle, then $\xi_{\mathrm{R}}$ denotes the real $2 n$-plane bundle obtained by "restriction of coefficients" to the reals. Also, $\xi^{*}$ denotes the complex conjugate bundle. We then have the following relation for any complex vector bundle $\xi$ :

$$
\xi_{R} \otimes C=\xi+\xi^{*} \quad \text { (Whitney sum) . }
$$

(see Hirzebruch, [4], p. 68, proof of Theorem 4.5.1). Moreover, for any

Received January 10, 1962. During the preparation of this note the author was partially supported by N. S. F. Grant G 18995. 
real vector bundle $\eta$,

$$
p_{i}(\eta)=(-1)^{i} c_{2 i}(\eta \otimes C),
$$

(Hirzebruch [4], p. 67).

(d) We will also need to make use of the properties of the ring $K(X)$ as summarized for example in $\S 2$ of Atiyah and Todd [1]. We will use their notation and results without any further comment.

3. The ring $K\left(P_{n}(\boldsymbol{H})\right)$. By proposition 2.3 of [1] the Chern character

$$
\operatorname{ch}: K\left(P_{n}(\boldsymbol{H})\right) \rightarrow H^{*}\left(P_{n}(\boldsymbol{H}), \boldsymbol{Q}\right)
$$

is a monomorphism.

Lemma 1. The image of this homomorphism, denoted by $\operatorname{ch} P_{n}(\boldsymbol{H})$, is the subring of $H^{*}\left(P_{n}(\boldsymbol{H}), \boldsymbol{Q}\right)$ generated by

$$
2 \cosh \sqrt{v}=2\left(1+v / 2 !+v^{2} / 4 !+\cdots+v^{n} /(2 n) !\right)
$$

where $v$ is an appropriately chosen generator of

$$
\left.H^{4}\left(P_{n}(\boldsymbol{H}), \boldsymbol{Z}\right) \subset H^{4}(\boldsymbol{H}), \boldsymbol{Q}\right) .
$$

Proof. Consider the well-known principal fibre bundle $\pi_{n}: S^{4 n+3} \rightarrow$ $P_{n}(\boldsymbol{H})$ with group $S p(1)$; let $\eta_{n}$ denote the associated bundle with fibre a quaternionic vector space of dimension 1. We assert that the total symplectic Pontrjagin class of this bundle is

$$
e\left(\eta_{n}\right)=1+e_{1}\left(\eta_{n}\right)=1+v
$$

where $v$ is an appropriately chosen generator of $H^{4}\left(P_{n}(\boldsymbol{H}), Z\right)$. This follows from the fact that $\pi_{n}: S^{4 n+3} \rightarrow P_{n}(\boldsymbol{H})$ is a universal bundle for the group $S p(1)$ (up to the dimension $4 n+2$ ), and that the integral cohomology ring of the classifying space for $S p(1)$ is a polynomial ring generated by the symplectic Pontrjagin class $e_{1}$ (see Borel and Hirzebruch, [2], § 9.6).

Let $\xi_{n}$ denote the complex vector bundle obtained from $\eta_{n}$ by "restriction of coefficients" to the complex numbers; the associated principal bundle is a $U(2)$-bundle which is the extension of $\pi_{n}: S^{4 n+3} \rightarrow P_{n}(\boldsymbol{H})$ under the standard inclusion $S p(1) \subset U(2)$. By $\S 9.6$ of [2],

$$
e_{1}\left(\eta_{n}\right)=-c_{2}\left(\xi_{n}\right)
$$

hence

$$
c\left(\xi_{n}\right)=1-v .
$$

The Chern character (see [2], §9.1) of $\xi_{n}$ is 


$$
\operatorname{ch}\left(\xi_{n}\right)=e^{y_{1}}+e^{y_{2}}
$$

where

$$
\left(1+y_{1}\right)\left(1+y_{2}\right)=c\left(\xi_{n}\right)=1-v
$$

Hence

$$
y_{1}+y_{2}=0, \quad y_{1} y_{2}=-v \text {. }
$$

From this we conclude that

$$
\begin{gathered}
y_{1}=-y_{2}, v=y_{1}^{2}, \\
y_{1}=\sqrt{v}, y_{2}=-\sqrt{v}, \\
\operatorname{ch}\left(\xi_{n}\right)=\exp (v)+\exp (-v)=2 \cosh \sqrt{v} .
\end{gathered}
$$

Hence $\operatorname{ch}\left(P_{n}(\boldsymbol{H})\right)$ contains the subring generated by $2 \cosh \sqrt{v}$; it remains to show that it is exactly equal to this subring. This is done by induction on $n$ exactly as in the proof of Proposition 3.1 of [1]. The details may be left to the reader.

Note that $\operatorname{ch} P_{n}(\boldsymbol{H})$ may be equivalently described as the subring of $H^{*}\left(P_{n}(\boldsymbol{H}), \boldsymbol{Q}\right)$ generated by

$$
w=2 \cosh \sqrt{v}-2=v+2 v^{2} / 4 !+\cdots+2 v^{n} /(2 n) ! \text {. }
$$

For many purposes this description of $\operatorname{ch} P_{n}(H)$ is more convenient; note that $w^{n+1}=0$, and $\left\{1, w, w^{2}, \cdots, w^{n}\right\}$ is a basis of $c h P_{n}(\boldsymbol{H})$ over the integers.

Lemma 1 and equation (1) above are both stated in terms of "appropriately" chosen generators, $v$ and $u$ respectively, of the infinite cyclic group $H^{4}\left(P_{n}(\mathbf{H}), \mathbf{Z}\right)$. Therefore $u= \pm v$. We assert that $u=+v$. To prove this, it obviously suffices to show that $\operatorname{ch}\left(\tau_{n} \otimes \mathbf{C}\right)$ belongs to the subring of $H^{*}\left(P_{n}(\mathbf{H}), \mathbf{Q}\right)$ generated by $2 \cosh V \bar{u}$, but that it does not belong to the subring of $H^{*}\left(P_{n}(\boldsymbol{H}), \boldsymbol{Q}\right)$ generated by $2 \cosh \sqrt{-u}$. This we will now do by an essentially straightforward, but rather lengthy, computation.

Lemma 2. The Chern character of $\tau_{n} \otimes \boldsymbol{C}$ is given by

$$
\operatorname{ch}\left(\tau_{n} \otimes C\right)=(4 n+4) \cosh \sqrt{u}-4 \cosh ^{2} \sqrt{u} .
$$

Proof. It follows from equations (1) and (3) that the total Chern class of $\tau_{n} \otimes C$ is given by

$$
c\left(\tau_{n} \otimes C\right)=(1-u)^{2 n+2}(1-4 u)^{-1} .
$$

To compute the Chern character of $\tau_{n} \otimes C$, we may proceed as follows: Write the total Chern class as a formal product

$$
c\left(\tau_{n} \otimes C\right)=\prod_{i=1}^{4 n}\left(1+x_{i}\right),
$$


where the $x_{i}$ 's have degree 2 . Then

$$
\operatorname{ch}\left(\tau_{n} \otimes C\right)=\sum_{i=1}^{4 n} \exp \left(x_{i}\right),
$$

To actually carry out the computation, take the logarithm of both sides of the equation

$$
\Pi\left(1+x_{i}\right)=(1-u)^{2 n+2}(1-4 u)^{-1},
$$

and use the MacLaurin series expansion of $\log (1+z)$ and $\log (1-z)$. The result is

$$
\sum_{k>0}(-1)^{k+1} s_{k} / k=-\sum_{k>0}\left(2 n+2-4^{k}\right) u^{k} / k,
$$

where

$$
s_{k}=\sum_{i=1}^{4 n} x_{i}^{k}
$$

Since each $x_{i}$ is of degree 2 , while $u$ is of degree 4 , we conclude from equation (4) that

$$
\begin{aligned}
s_{k} & =0 \quad \text { for } k \text { odd }, \\
s_{2 k} & =2\left(2 n+2-4^{k}\right) u^{k} .
\end{aligned}
$$

Therefore

$$
\begin{aligned}
\operatorname{ch}\left(\tau_{n} \otimes C\right) & =\sum_{i=1}^{4 n} \exp \left(x_{i}\right)=\sum_{i=1}^{4 n} \sum_{k} x_{i}^{k} / k ! \\
& =4 n+\sum_{k>0} s_{k} / k ! \\
& =4 n+\sum_{k>0} 2\left(2 n+2-4^{k}\right) u^{k} /(2 k) ! \\
& =(4 n+4) \cosh \sqrt{u}-2 \cosh \sqrt{4 u}-2 \\
& =(4 n+4) \cosh \sqrt{u}-4 \cosh ^{2} \sqrt{u},
\end{aligned}
$$

as was to be proved.

It is obvious from this formula that $\operatorname{ch}\left(\tau_{n} \otimes C\right)$ belongs to the subring of $H^{*}\left(P_{n}(\boldsymbol{H}), \boldsymbol{Q}\right)$ generated by $2 \cosh \sqrt{u}$; we must now prove that $\operatorname{ch}\left(\tau_{n} \otimes C\right)$ does not belong to the subring generated by

$$
2 \cosh \sqrt{-u}=2 \cos \sqrt{u} .
$$

Assume the contrary; then there exist integers $a_{0}, a_{1}, \cdots, a_{n}$ such that

$$
\operatorname{ch}\left(\tau_{n} \otimes C\right)=\sum_{k=0}^{n} a_{k}(2 \cos \sqrt{u}-2)^{k},
$$

that is, 


$$
\begin{aligned}
& 2 \sum_{k=1}^{n}\left(2 n+2-4^{k}\right) u^{k} /(2 k) ! \\
& =\sum_{k=1}^{n} a_{k}\left(-u+2 u^{2} / 4 !-2 u^{3} / 6 !+\cdots \pm 2 u^{n} /(2 n) !\right)^{k} .
\end{aligned}
$$

If we compare coefficients of $u, u^{2}, u^{3}$, and $u^{4}$ in this equation, we obtain

$$
\begin{aligned}
& a_{1}=-2 n+2, \\
& a_{2}=(n-4) / 3, \\
& a_{3}=(7-n) / 18, \\
& a_{4}=(5 n-47) / 504 .
\end{aligned}
$$

For $n=2$ or $3, a_{2}$ is not an integer; for $n<7, a_{3}$ is not an integer; and for any value of $n$, it is impossible that both $a_{3}$ and $a_{4}$ are integers. For, if $a_{3}$ is an integer, then

$$
n \equiv 7 \bmod 18 \text { or } 5 n \equiv 35 \bmod 18 \text {, }
$$

while if $a_{4}$ is an integer, then

$$
5 n \equiv 47 \bmod 18
$$

which is a contradiction.

This completes the proof that $u=+v$.

4. Proof of the theorem. Assume $\tau_{n}$ admits an almost complex structure $\theta_{n}$; we will show that this leads to a contradiction.

$\theta_{n}$ is a complex $2 n$-plane bundle over $P_{n}(\boldsymbol{H})$ such that $\tau_{n}=\theta_{n \boldsymbol{R}}$. Then by equation (2)

$$
\tau_{n} \otimes \boldsymbol{C}=\theta_{n \mathbf{R}} \otimes \boldsymbol{C}=\theta_{n}+\theta_{n}^{*} .
$$

Next, recall that

$$
\operatorname{ch}_{i}\left(\theta_{n}^{*}\right)=(-1)^{i} \operatorname{ch}_{i}\left(\theta_{n}\right)
$$

where $c h_{i}$ denotes the component of $c h$ of degree $2 i$. However, since the base space of the bundle $\theta_{n}$ is $P_{n}(\boldsymbol{H})$,

$$
\operatorname{ch}\left(\theta_{n}^{*}\right)=\operatorname{ch}\left(\theta_{n}\right) \text {. }
$$

Therefore

$$
\operatorname{ch}\left(\tau_{n} \otimes \mathbf{C}\right)=2 \operatorname{ch}\left(\theta_{n}\right) .
$$

It follows from Lemma 2 that

$$
\begin{aligned}
\operatorname{ch}\left(\theta_{n}\right) & =(2 n+2) \cosh \sqrt{u}-2 \cosh ^{2} \sqrt{u} \\
& =-\frac{1}{2}(2 \cosh \sqrt{u}-2)^{2}+(n-1)(2 \cosh \sqrt{u}-2)+2 n .
\end{aligned}
$$

This is the desired contradiction, since the Chern character of any complex 
vector bundle is an integral linear combination of the powers of $w=(2 \cosh \sqrt{u}-2)$.

REMARK. We have actually proved a slightly stronger theorem, in that we have shown that for any integer $n>1, P_{n}(\boldsymbol{H})$ does not admit a "generalized almost complex structure" as defined by Hirzebruch in his lecture [5]. As Hirzebruch remarks, this can be proved easily by induction on $n$, once the case $n=2$ is taken care of. However, the above computations of $\operatorname{ch}\left(P_{n}(\boldsymbol{H})\right)$ and $\operatorname{ch}\left(\tau_{n} \otimes \boldsymbol{C}\right)$ may be of some independent interest.

\section{BIBLIOGRAPHY}

1. M. F. Atiyah and J. A. Todd, On complex Stiefel manifolds, Proc. Cambridge Phil. Soc., 56 (1960), 343-353.

2. A. Borel and F. Hirzebruch, Characteristic classes and homogeneous spaces, I. Amer. J. Math., 80 (1958), 458-538.

3. F. Hirzebruch, Über die quaternionalen projektiven Räume S.-B. Math. Nat. K1. Bayer. Akad. Wiss. 1953, (1954), 301-312.

4. - Neue Topologische Methoden in der Algebraischen Geometrie, Ergeb. der Math. u. Grenzgebiete (N. F.) 9, Berlin, 1956.

5. — Komplexe Manigfaltigkeiten, Proc. Int. Congress. Math., 14-21 August 1958, Edinburgh, pp. 119-136. 


\section{PACIFIC JOURNAL OF MATHEMATICS}

\section{EDITORS}

\author{
Ralph S. Phillips \\ Stanford University \\ Stanford, California \\ M. G. Arsove \\ University of Washington \\ Seattle 5 , Washington
}

\author{
A. L. Whiteman \\ University of Southern California \\ Los Angeles 7, California \\ Lowell J. Paige \\ University of California \\ Los Angeles 24, California
}
E. F. BECKENBACH
D. DERRY
ASSOCIATE EDITORS
T. M. CHERRY
M. OHTSUKA
H. L. ROYDEN
E. G. STRAUS
E. SPANIER
F. WOLF

\section{SUPPORTING INSTITUTIONS}

\author{
UNIVERSITY OF BRITISH COLUMBIA \\ CALIFORNIA INSTITUTE OF TECHNOLOGY \\ UNIVERSITY OF CALIFORNIA \\ MONTANA STATE UNIVERSITY \\ UNIVERSITY OF NEVADA \\ NEW MEXICO STATE UNIVERSITY \\ OREGON STATE UNIVERSITY \\ UNIVERSITY OF OREGON \\ OSAKA UNIVERSITY \\ UNIVERSITY OF SOUTHERN CALIFORNIA
}

\author{
STANFORD UNIVERSITY \\ UNIVERSITY OF TOKYO \\ UNIVERSITY OF UTAH \\ WASHINGTON STATE UNIVERSITY \\ UNIVERSITY OF WASHINGTON \\ AMERICAN MATHEMATICAL SOCIETY \\ CALIFORNIA RESEARCH CORPORATION \\ SPACE TECHNOLOGY LABORATORIES \\ NAVAL ORDNANCE TEST STATION
}

Mathematical papers intended for publication in the Pacific Journal of Mathematıcs should be typewritten (double spaced), and the author should keep a complete copy. Manuscripts may be sent to any one of the four editors. All other communications to the editors should be addressed to the managing editor, L. J. Paige at the University of California, Los Angeles 24, California.

50 reprints per author of each article are furnished free of charge; additional copies may be obtained at cost in multiples of 50 .

The Pacific Journal of Mathematics is published quarterly, in March, June, September, and December. Effective with Volume 13 the price per volume (4 numbers) is $\$ 18.00$; single issues, $\$ 5.00$. Special price for current issues to individual faculty members of supporting institutions and to individual members of the American Mathematical Society: $\$ 8.00$ per volume; single issues $\$ 2.50$. Back numbers are available.

Subscriptions, orders for back numbers, and changes of address should be sent to Pacific Journal of Mathematics, 103 Highland Boulevard, Berkeley 8, California.

Printed at Kokusai Bunken Insatsusha (International Academic Printing Co., Ltd.), No. 6, 2-chome, Fujimi-cho, Chiyoda-ku, Tokyo, Japan.

PUBLISHED BY PACIFIC JOURNAL OF MATHEMATICS, A NON-PROFIT CORPORATION

The Supporting Institutions listed above contribute to the cost of publication of this Journal, but they are not owners or publishers and have no responsibility for its content or policies. 


\section{Pacific Journal of Mathematics}

\section{Vol. 12 , No. 4 \\ April, 1962}

Tsuyoshi Andô, On fundamental properties of a Banach space with a cone ..... . 1163

Sterling K. Berberian, A note on hyponormal operators ................ 1171

Errett Albert Bishop, Analytic functions with values in a Frechet space . . . . . . . 1177

(Sherman) Elwood Bohn, Equicontinuity of solutions of a quasi-linear equation ............................................ 1193

Andrew Michael Bruckner and E. Ostrow, Some function classes related to the class of convex functions . . . . . . . . . . . . . . . . . . . . . . . . 1203

J. H. Curtiss, Limits and bounds for divided differences on a Jordan curve in the complex domain . . ................................. 1217

P. H. Doyle, III and John Gilbert Hocking, Dimensional invertibility . . . . . . . . 1235

David G. Feingold and Richard Steven Varga, Block diagonally dominant matrices and generalizations of the Gerschgorin circle theorem ................. 1241

Leonard Dubois Fountain and Lloyd Kenneth Jackson, A generalized solution of the boundary value problem for $y^{\prime \prime}=f\left(x, y, y^{\prime}\right) \ldots \ldots \ldots \ldots \ldots \ldots \ldots \ldots \ldots$

Robert William Gilmer, Jr., Rings in which semi-primary ideals are primary. . . . . 1273

Ruth Goodman, K-polar polynomials .......................... 1277

Israel Halperin and Maria Wonenburger, On the additivity of lattice completeness ........................................... 1289

Robert Winship Heath, Arc-wise connectedness in semi-metric spaces . . . . . . . . 1301

Isidore Heller and Alan Jerome Hoffman, On unimodular matrices . . . . . . . . . . . 1321

Robert G. Heyneman, Duality in general ergodic theory . . . . . . . . . . . . . . . 1329

Charles Ray Hobby, Abelian subgroups of p-groups . . . . . . . . . . . . . . . 1343

Kenneth Myron Hoffman and Hugo Rossi, The minimum boundary for an analytic

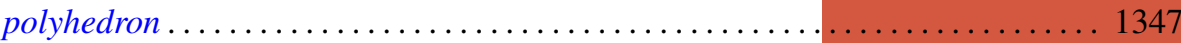

Adam Koranyi, The Bergman kernel function for tubes over convex cones ........ 1355

Pesi Rustom Masani and Jack Max Robertson, The time-domain analysis of a continuous parameter weakly stationary stochastic proces.

William Schumacher Massey, Non-existence of almost-complex structures on

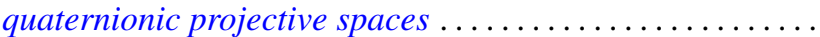

Deane Montgomery and Chung-Tao Yang, A theorem on the action of $\mathrm{SO}(3) \ldots . .1385$

Ronald John Nunke, A note on Abelian group extensions . . . . . . . . . . . . . 1401

Carl Mark Pearcy, A complete set of unitary invariants for operators generating finite $W^{*}$-algebras of type $I$

Edward C. Posner, Integral closure of rings of solutions of linear differential equations.

Duane Sather, Asymptotics. III. Stationary phase for two parameters with an application to Bessel functions.

J. Śladkowska, Bounds of analytic functions of two complex variables in domains

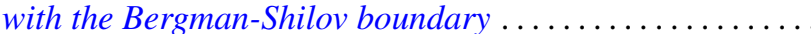

Joseph Gail Stampfli, Hyponormal operators .

George Gustave Weill, Some extremal properties of linear combinations of kernels

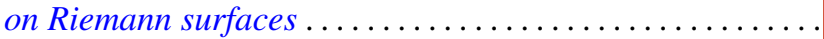

